\title{
Progesterone receptor enhances breast cancer cell motility and invasion via extranuclear activation of focal adhesion kinase
}

\author{
Xiao-Dong Fu, ${ }^{1,2 *}$, Lorenzo Goglia ${ }^{1 *}$, Angel Matias Sanchez ${ }^{1}$, Marina Flamini ${ }^{1}$, \\ Maria S Giretti ${ }^{1}$, Veronica Tosi ${ }^{1}$, Andrea R Genazzani ${ }^{1}$ and Tommaso Simoncini ${ }^{\prime}$ \\ ${ }^{1}$ Molecular and Cellular Gynecological Endocrinology Laboratory (MCGEL), Department of Reproductive Medicine and Child \\ Development, University of Pisa, Pisa 56100, Italy \\ ${ }^{2}$ Department of Physiology, Zhongshan School of Medicine, Sun Yat-sen University, Guangzhou 510080, \\ People's Republic of China \\ (Correspondence should be addressed to T Simoncini; Email: t.simoncini@obgyn.med.unipi.it) \\ *(X-D Fu and L Goglia contributed equally to this work)
}

\begin{abstract}
While progesterone plays multiple roles in the process of breast development and differentiation, its role in breast cancer is less understood. We have shown previously that progestins stimulate breast cancer cell migration and invasion because of the activation of rapid signaling cascades leading to modifications in the actin cytoskeleton and cell membrane that are required for cell movement. In this study, we have investigated the effects of progesterone on the formation of focal adhesion (FA) complexes, which provide anchoring sites for cell attachment to the extracellular matrix during cell movement and invasion. In T47-D breast cancer cells, progesterone rapidly enhances FA kinase (FAK) phosphorylation at $\mathrm{Tyr}^{397}$ in a time- and concentration-dependent manner. As a result, exposure to progesterone leads to increased formation of FA complexes within specialized cell membrane protrusions. The cascade of events required for this phenomenon involves progesterone receptor interaction with the tyrosine kinase c-Src, which activates the phosphatidylinositol-3-kinase/Akt pathway and the small GTPase RhoA/Rho-associated kinase complex. In the presence of progesterone, T47-D breast cancer cells display enhanced horizontal migration and invasion of three-dimensional matrices, which is reversed by small interfering RNAs abrogating FAK. In conclusion, progesterone promotes breast cancer cell movement and invasion by facilitating the formation of FA complexes via the rapid regulation of FAK. These results provide novel mechanistic views on the effects of progesterone on breast cancer progression, and may in the future be helpful to develop new strategies for the treatment of endocrine-sensitive breast cancers.
\end{abstract}

Endocrine-Related Cancer (2010) 17 431-443

\section{Introduction}

Progesterone is a major regulator of breast epithelial cell proliferation and differentiation; however, the connection between this hormone and breast cancer is still a matter of debate (Yager \& Davidson 2006, Hankinson $\&$ Eliassen 2007), particularly in the setting of hormonal replacement after menopause. In this regard, the Multiethnic Cohort and Women's Health Initiative trials recently documented that postmenopausal women receiving estroprogestin therapy are at increased risk of breast cancer compared with those receiving estrogen only, supporting the concept that progesterone may contribute to the development or progression of breast cancer after menopause (Hwang et al. 2002, Rossouw et al. 2002, Anderson et al. 2004).

Local and distant breast cancer progression is the main reason for morbidity and mortality (Weigelt et al. 2005). The metastatic process requires a series of events that allows cancer cells to invade the 
extracellular environment, and eventually to enter blood and lymphatic vessels (Yamaguchi et al. 2005, Christofori 2006). On the basis of this phenomenon, the cancer cells are able to remodel the actin cytoskeleton and to develop a leading edge where membrane protrusions such as filopodia and lamellipodia get in contact with the extracellular matrix (ECM) via anchorage proteins and focal adhesions (FAs; Yamazaki et al. 2005). These connections provide the platform to generate the locomotive force that enables cancer cells to move via the activation of the actomyosin contractile machinery (Yamazaki et al. 2005).

We recently discovered that sex steroids, including estrogen and progesterone, promote endothelial as well as breast cancer cell migration by inducing the formation of membrane protrusions and the remodeling of the actin cytoskeleton. These events are largely dependent on the rapid regulation of actin-binding proteins belonging to the ezrin/radixin/moesin (ERM) family, and are triggered by extranuclear signaling of steroid receptors to membrane-bound $G$ proteins (Simoncini et al. 2006, Fu et al. 2008a,b, Giretti et al. 2008). Whether sex steroids also alter breast cancer cell adhesion to the ECM through the regulation of FAs is currently unknown.

FAs are composed of a complex group of structural proteins and signaling molecules, including the tyrosine kinases c-Src and FA kinase (FAK), integrin proteins, actin-binding proteins such as vinculin, and adaptor proteins such as paxillin (Romer et al. 2006). FAs provide the mechanical linkage between the actomyosin network and the ECM, and represent sites where a number of intra- and extracellular signaling events regulating cell migration take place (Arnaout et al. 2007). FAK is the key enzyme regulating the formation of FAs. In the quiescent state, FAK is auto-inhibited by an intramolecular interaction of the $\mathrm{N}$-terminal four.1-ezrin-radixin-moesin (FERM) domain with the kinase domain. Under the stimulation of multiple factors, FAK is activated via the phosphorylation at $\mathrm{Tyr}^{397}$, leading to the subsequent phosphorylation of $\mathrm{Tyr}^{576 / 577}$ in the catalytic loop which is necessary for the full activation of the kinase domain. Active FAK begins to partner with cell membrane integrins with the assistance of other proteins such as p130CAS, paxillin, and vinculin, resulting in FA formation and endowing cells with higher motility (van Nimwegen \& van de Water 2007). Overexpression and/or enhanced activity of FAK have been identified in aggressive tumors (Owens et al. 1995, Rovin et al. 2002). Moreover, FAK expression is higher in metastatic cancer specimens compared with the primary sites (Sood et al. 2004).
In this study, we have explored the regulatory actions of progesterone on FAK activity, and the effects on breast cancer cell cytoskeleton remodeling, migration, and invasion. Moreover, we have characterized the signaling pathways initiated by progesterone receptor (PR) that lead to FAK activation.

\section{Materials and methods}

\section{Cell cultures and treatments}

T47-D breast cancer cells were incubated in phenol red-free RPMI 1640 medium containing 10\% FCS, $0.2 \mathrm{UI} / \mathrm{ml}$ insulin, L-glutamine, and penicillinstreptomycin under a $5 \% \mathrm{CO}_{2}$ atmosphere at $37{ }^{\circ} \mathrm{C}$. Before starting the experiments in which nontranscriptional effects were investigated, cells were kept in phenol red-free DMEM containing no FBS for $8 \mathrm{~h}$. Whenever an inhibitor was used, the compound was added $30 \mathrm{~min}$ before starting the treatments. Progesterone, pertussis toxin (PTX), Y-27632, PD98059, and wortmannin were obtained from SigmaAldrich. 4-Amino-5-(4-chlorophenyl)-7-(t-butyl) pyrazolo (3,4-d) pyrimidine (PP2) was obtained from Calbiochem (EMD Biosciences, Darmstadt; Germany). ORG 31710 was a kind gift from Dr Lenus Kloosterboer and Organon Akzo Nobel (Oss, The Netherlands).

\section{Immunoblottings}

Cell lysates were separated by SDS-PAGE. Antibodies used were as follows: FAK (\#3285, Cell Signaling Technology, Danvers, MA, USA), Tyr ${ }^{397}$-phosphoFAK (\#3283, Cell Signaling Technology), Tyr ${ }^{576 / 577}$ phospho-FAK (\#3281, Cell Signaling Technology), PR (sc-539, Santa Cruz Biotechnology Inc, Santa Cruz, CA, USA), Thr ${ }^{34}$-P-Akt (07-789, Upstate, Lake Placid, NY, USA), and Akt (9272, Cell Signaling Technology). Primary and secondary antibodies were incubated with the membranes using a standard technique (Simoncini et al. 2000). Immunodetection was accomplished using enhanced chemiluminescence. Chemiluminescence was acquired with a quantitative digital imaging system (Quantity One, Bio-Rad) allowing to check for saturation. Overall emitted photons were quantified for each band, particularly for loading controls, which were homogeneously loaded.

\section{Kinase assays}

T47-D cells were harvested in $20 \mathrm{mM}$ Tris- $\mathrm{HCl}$, $10 \mathrm{mM}$ EDTA, $100 \mathrm{mM} \mathrm{NaCl}, 0.5 \%$ octylphenoxy polyethoxyethanol (IGEPAL), and $0.1 \mathrm{mg} / \mathrm{ml}$ 
phenylmethylsulfonyl fluoride (PMSF). Equal amounts of cell lysates were immunoprecipitated with Rhotekin RBD agarose (14-383, Upstate) versus GTP-RhoA or an antibody versus Rho-associated kinase (ROCK-2; C-20, Santa Cruz). The immunoprecipitates were washed three times with a buffer containing $20 \mathrm{mM}$ Tris- $\mathrm{HCl}, 10 \mathrm{mM}$ EDTA, $150 \mathrm{mM} \mathrm{NaCl}, 0.1 \%$ IGEPAL, and $0.1 \mathrm{mg} / \mathrm{ml}$ PMSF. For ROCK-2 activity assay, two additional washes were performed in a kinase assay buffer (20 mM 3-(N-morpholino)propanesulfonic acid (MOPS), $25 \mathrm{mM} \beta$-glycerophosphate, $5 \mathrm{mM}$ EGTA, and $1 \mathrm{mM}$ dithiothreitol), and therefore, the samples were resuspended in this buffer. Five micrograms of de-phosphorylated myelin basic protein (MBP; Upstate) together with $500 \mu \mathrm{M}$ ATP and $75 \mathrm{mM} \mathrm{MgCl}_{2}$ were added to each sample, and the reaction was started at $30{ }^{\circ} \mathrm{C}$ for $20 \mathrm{~min}$. The reaction was stopped by placing the samples on ice, and by resuspending the samples in the Laemmli buffer. The samples were separated with SDS-PAGE, and western analysis was performed using antibodies recognizing RhoA (sc-418, Santa Cruz) or $\mathrm{Thr}^{98}$. P-MBP (05-429, Upstate).

\section{Cell immunofluorescence}

T47-D breast cancer cells were grown on cover slips and exposed to treatments. Cells were fixed with $4 \%$ paraformaldehyde for $30 \mathrm{~min}$ and permeabilized with $0.1 \%$ Triton $\mathrm{X}$ for $5 \mathrm{~min}$. Blocking was performed with $3 \%$ normal serum for $20 \mathrm{~min}$. Cells were incubated with antibodies against $\mathrm{Tyr}^{397}$-phospho-FAK or vinculin (sc-7648, Santa Cruz). After washing, the nuclei were counterstained with 4'-6-diamidino-2-phenylindole (DAPI; Sigma), and actin was stained with Texas Red phalloidin (Sigma). The cover slips were mounted with Vectashield mounting medium (Vector Laboratories, Burlingame, CA, USA). Immunofluorescence was visualized using an Olympus BX41 microscope, and recorded with a high-resolution DP70 Olympus digital camera. Pictures were photographed.

\section{Transfection experiments}

On-TARGETplus SMARTpool small interfering RNAs (siRNA) reagents against human MAPK (NM138957), ROCK-2 (NM-004850), Src (NM-198291), FAK (NM-005607), and control siRNA (D-001810-0105) were purchased from Dharmacon (Thermo Fisher Scientific Inc., Waltham, MA, USA). T47-D cells were transfected with siRNA using Lipofectamine (Invitrogen) according to the protocol. Cells (40\% confluent) were serum-starved for $1 \mathrm{~h}$ followed by incubation with $100 \mathrm{nM}$ target siRNA or control siRNA for $6 \mathrm{~h}$ in serum-free media. The serumcontaining media were then added (10\% serum final concentration) for $42 \mathrm{~h}$ before the experiments, and/or functional assays were conducted. Target protein silencing was assessed through protein analysis up to $48 \mathrm{~h}$ after transfection.

Each plasmid $(15 \mu \mathrm{g})$ was transfected into T47-D breast cancer cells using Lipofectamine (Invitrogen) according to the manufacturer's instructions. The transfected plasmids were as follows: RhoA T19 and RhoA G14V, p85 $\alpha$ or dominant-negative p $85 \alpha$ $(\Delta \mathrm{p} 85 \alpha)$. These constructs were obtained from the Guthrie cDNA Resource Center (www.cdna.org). All the inserts were cloned in pcDNA3.1+. As control, parallel cells were transfected with empty pcDNA3.1 + plasmid. Cells $(60-70 \%$ confluent $)$ were treated $24 \mathrm{~h}$ after transfection, and cellular extracts were prepared according to the experiments to be performed.

\section{Cell migration assays}

Cell migration was assayed with razor scrape assays as described previously (Simoncini et al. 2006). Briefly, a razor blade was pressed through the confluent T47-D breast cancer cell monolayer into the plastic plate to mark the starting line. T47-D cells were swept away on one side of this line. Cells were washed, and $2.0 \mathrm{ml}$ of DMEM containing steroid-deprived FBS and gelatin $(1 \mathrm{mg} / \mathrm{ml})$ were added. Cytosine $\beta$-D-arabinofuranoside hydrochloride (Ara-C, Sigma) $(10 \mu \mathrm{M})$, a selective inhibitor of DNA synthesis which does not inhibit RNA synthesis, was used $1 \mathrm{~h}$ before the test substance was added. Ara-C easily enters into the nucleus and it incorporates into the DNA, inhibiting DNA replication by forming cleavage complexes with topoisomerase I, resulting in DNA fragmentation. Although the half-life of Ara-C is $<1 \mathrm{~h}$ in most cell lines, more than $80 \%$ of Ara-C is retained by the DNA $24 \mathrm{~h}$ after drug removal (Grem et al. 1995). Preliminary experiments with these cells confirmed complete suppression of cell division in the presence of Ara-C as used in these experiments. Migration was monitored for $48 \mathrm{~h}$. Every $12 \mathrm{~h}$, fresh medium and treatment were replaced. Cells were digitally imaged, and migration distance was measured using phase-contrast microscopy.

\section{Cell invasion assays}

Cell invasion was assayed following the standard method using the BD BioCoatTM Growth Factor 
Reduced (GFR) Matrigel Invasion Chamber (BD Bioscience, San Jose, CA, USA). In brief, after rehydrating the GFR Matrigel inserts, the test substance was added to the wells. An equal number of control inserts (no GFR Matrigel coating) were prepared as control. T47-D cell suspension $(0.5 \mathrm{ml}$, $2.5 \times 10^{4}$ cells $/ \mathrm{ml}$ ) was added to the inside of the inserts. The chambers were incubated for $24 \mathrm{~h}$ at $37^{\circ} \mathrm{C}$ in $5 \% \mathrm{CO}_{2}$ atmosphere. After incubation, non-invading cells were removed from the upper surface of the membrane using cotton-tipped swabs. Then, the cells on the lower surface of the membrane were stained with Diff-Quick stain. The invading cells were observed and photographed under the microscope at $100 \times$ magnification. Cells were counted in the central field of triplicate membranes. The invasion index was calculated as the percentage invasion test cell/percentage invasion control cell.

\section{Statistical analysis}

All values are expressed as mean \pm s.D. Statistical differences between mean values were determined by ANOVA, followed by Fisher's protected least significant difference. All differences were considered significant at $P<0.05$.

\section{Results}

\section{Progesterone rapidly induces FAK phosphorylation and the formation of FA complexes}

Treatment of T47-D cells with progesterone $(100 \mathrm{nM})$ resulted in rapid increases in $\mathrm{Tyr}^{397}$ phosphorylation of FAK (which corresponds to activation) (van Nimwegen \& van de Water 2007), with a significant effect from $5 \mathrm{~min}$, a phosphorylation peak at $30 \mathrm{~min}$, and a decline to basal levels after $1 \mathrm{~h}$ (Fig. 1A). In parallel, the cell
A
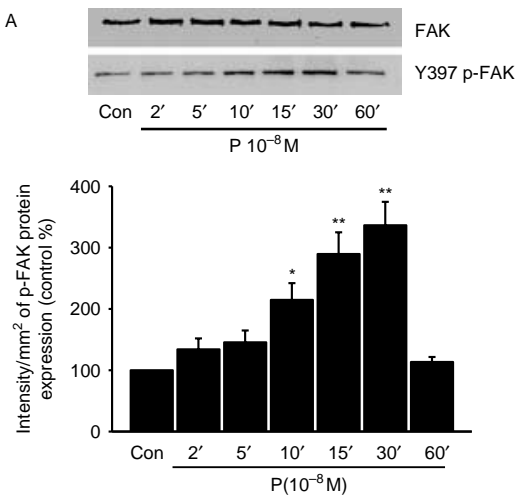

D

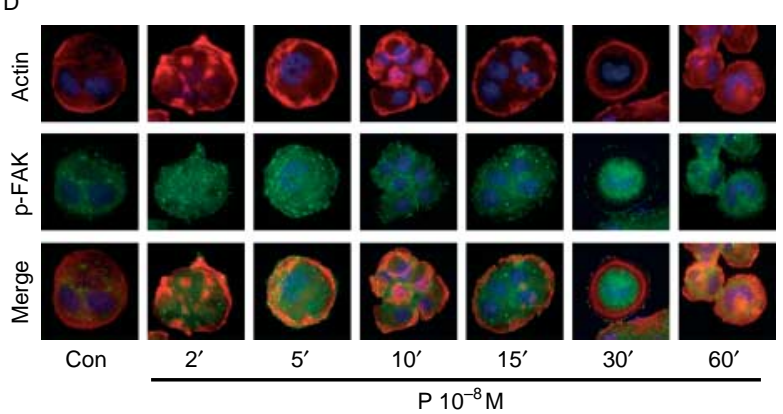

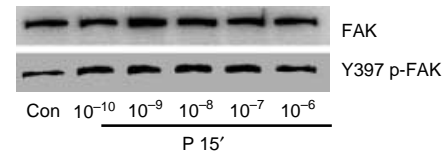
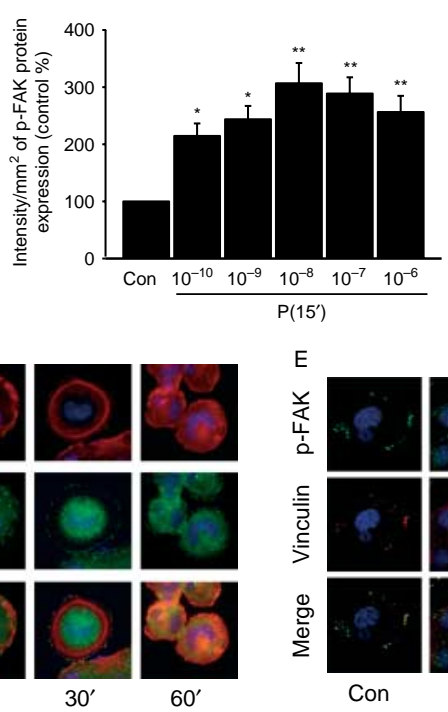


Figure 1 Progesterone $(P)$ activates FAK and induces rapid actin cytoskeleton rearrangement in T47-D cells. (A-C) The time- and dose-dependent FAK activation in T47-D breast cancer cells after treatment with $P$. Total cell amount of wild-type (FAK) or Tyr ${ }^{397}$ phosphorylated FAK (Y397 p-FAK) (A and B) or Tyr ${ }^{576 / 577}$-phosphorylated FAK (Y576/577 p-FAK) (C) is shown with western blot. p-FAK densitometry values were adjusted to FAK intensity, and were then normalized to the control sample. ${ }^{\star} P<0.05$ versus corresponding control; ${ }^{* *} P<0.01$ versus corresponding control. (D) T47-D cells were treated with $P$ (10 nM) for the indicated time. Then, the cells were stained with anti-phospho-Tyr ${ }^{397}$ focal adhesion kinase ( $p$-FAK) linked to FITC, and actin was stained with phalloidin linked to Texas Red and nuclei were counterstained with DAPI. (E) Cells were treated with $\mathrm{P}$ (10 nM) for different times. Then, the cells were stained with anti-phospho-Tyr ${ }^{397}$ focal adhesion kinase (p-FAK) linked to FITC (green) and anti-vinculin linked to Texas Red (red). Nuclei were counterstained with DAPI. Double staining analysis (yellow signal) revealed areas of co-localization of the two proteins. All the experiments were repeated three times with consistent results, and the representative images are shown. 
content of wild-type FAK did not change during this time frame (Fig. 1A). FAK phosphorylation at $\mathrm{Tyr}^{397}$ or at $\mathrm{Tyr}^{576 / 577}$ was found throughout a range of progesterone concentrations (0.1-1000 nmol/l; Fig. 1B and C). These concentrations largely fall within the physiological range (fertile life levels $0.3-9 \mathrm{nmol} / \mathrm{l}$, during pregnancy from 3 to $300 \mathrm{mmol} / \mathrm{l}$; Rousell et al. 1979).

Sub-cellular localization of phosphorylated FAK in T47-D cells was examined by immunofluorescence analysis. In vehicle-treated cells, the level of phosphorylated FAK was relatively low, and actin fibers were longitudinally arranged in the cytoplasm (Fig. 1D). Short-term exposure to progesterone $(10 \mathrm{nM})$ led to increased expression of phosphorylated FAK and to actin rearrangement, with a significant increase in the thickness of the cell membrane (Fig. 1D). Phosphorylated FAK concentrated at the cell membrane at sites of ongoing actin remodeling (Fig. 1D). These alterations could be observed as early as $2 \mathrm{~min}$, and began to revert to baseline after $1 \mathrm{~h}$ (Fig. 1D).

In order to ascertain the role of phosphorylated FAK in the formation of FA complexes, we examined the co-localization of phosphorylated FAK and vinculin, an actin-binding protein frequently used as a marker for FA complexes (Ziegler et al. 2006). Progesterone $(10 \mathrm{nM})$ induced a quick increase in phosphorylated FAK cell content, and a time-consistent co-localization of phosphorylated FAK and vinculin was indicated by the overlay of the stainings for the two proteins, showing a point-like merged signal at the edge of the membrane that indicates FA sites (Fig. 1E).

\section{PR signaling to FAK requires c-Src and phosphatidylinositol-3-kinase/Akt}

The rapid time lapse of FAK activation and deactivation suggests that progesterone-induced activation of this enzyme is likely to be mediated by extranuclear mechanisms (Fu \& Simoncini 2007). To clarify the signaling intermediates implicated in FAK activation by PR, we interfered with some of the cascades that mediate extranuclear actions of progesterone. Blockade of $\mathrm{PR}$ with the pure PR antagonist ORG 31710 completely abolished progesterone-dependent FAK activation, confirming that PR is the steroid receptor used to signal to FAK (Fig. 2A). Moreover, inhibition of phosphatidylinositol-3-kinase (PI3K) with wortmannin, interference with c-Src with PP2, or inhibition of the ROCK-2 with Y-27632 prevented the phosphorylation of FAK (Fig. 2A), indicating that in the presence of progesterone, $\mathrm{PR}$ signals to $\mathrm{FAK}$ via c-Src, $\mathrm{PI} 3 \mathrm{~K}$, and ROCK-2.

On the other hand, the G protein inhibitor PTX as well as the inhibitor of the extracellular regulated kinase 1/2 (ERK1/2), PD98059, or the transfection of siRNAs silencing ERK1/2 (Fig. 2B) was ineffective, suggesting that PR is not coupled to $G$ proteins nor to the ERK1/2 MAPK cascade to drive FAK phosphorylation (Fig. 2A-C).

PR interacts with the tyrosine kinase c-Src (Boonyaratanakornkit et al. 2001), and this process is linked to the activation of PI3K (Koga et al. 2006). This was confirmed by our results showing that progesterone induces a two- to three-fold increase in phosphorylation of the PI3K downstream effector, protein kinase Akt (Fig. 2D). The c-Src inhibitor PP2 blocked the phosphorylation of Akt induced by progesterone (Fig. 2D). Progesterone failed to activate Akt and FAK when c-Src expression was silenced with siRNAs (Fig. 2E). In addition, transfection of T47-D cells with a dominant-negative form of the regulatory subunit of PI3K, p85 $\alpha(\Delta \mathrm{p} 85 \alpha)$, resulted in the impairment of the PR-dependent FAK activation. As control, the transfection of a wild-type p85 $\alpha$ construct (WT p $85 \alpha$ ) did not alter FAK activation induced by progesterone (Fig. 2F). The p85 plasmids were overexpressed in both conditions (Fig. 2F), implying an efficient transfection in our experimental settings. Taken together, these results suggest that the c-Src-dependent activation of PI3K/Akt is implicated in PR signaling.

\section{PR signaling to FAK: role of RhoA and ROCK-2}

The small GTPase RhoA and its downstream effector ROCK-2 play a central role in regulating the actin cytoskeleton by delivering upstream signaling events to actin-regulatory proteins such as moesin or FAK (Torsoni et al. 2005, Fu et al. 2008b). Treatment of T47-D cells with progesterone increased the amount of active, GTP-bound RhoA (Fig. 3A) and of functionally activated ROCK-2, shown by enhanced Thr phosphorylation of the bait protein MBP by ROCK-2 immunoprecipitates (Fig. 3B). FAK phosphorylation was ligand independently induced by transient transfection of a RhoA constitutively active construct (RhoA G14V; Fig. 3C). In parallel, transfection of a dominant-negative RhoA construct (RhoA T19N) resulted in a significant reduction in progesterone-induced FAK phosphorylation (Fig. 3C). In parallel, silencing of ROCK-2 with siRNAs prevented the progesterone-related FAK activation (Fig. 3D). 
A
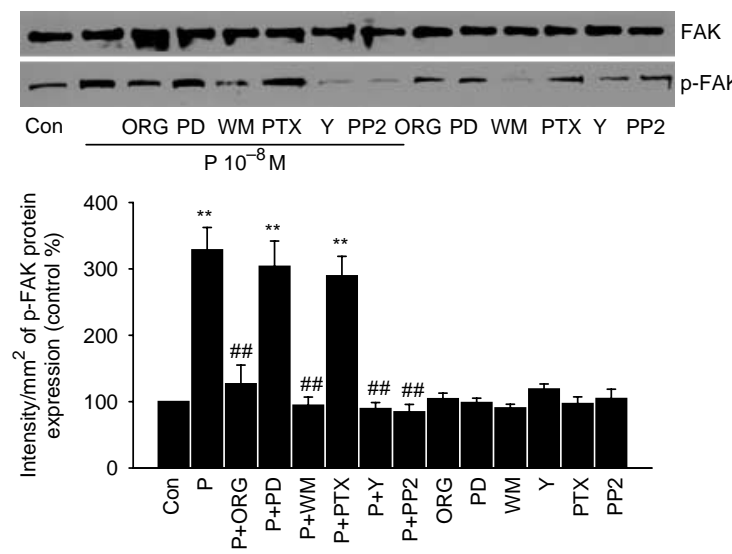

D
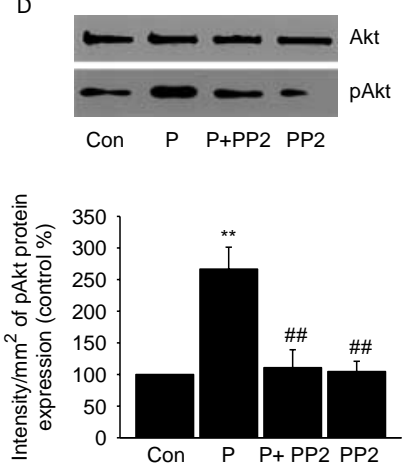

B

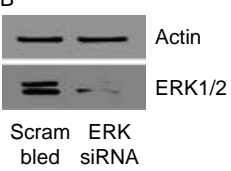

C
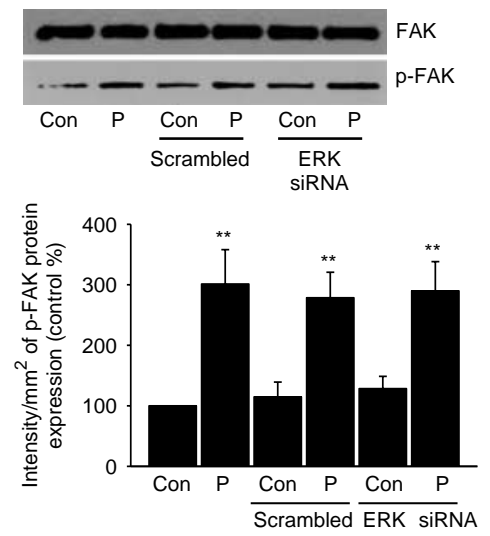

$\mathrm{F}$
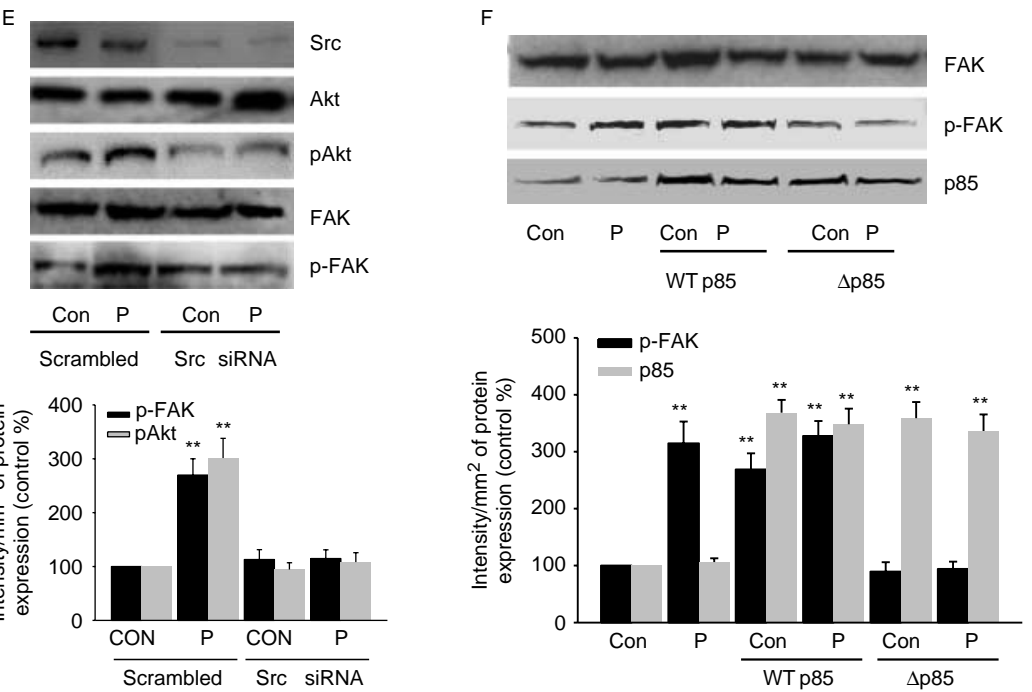

Figure 2 c-Src and phosphatidylinositol-3-kinase (PI3K)/Akt are implicated in progesterone-induced FAK phosphorylation. (A) T47-D cells were exposed to $10 \mathrm{nM}$ progesterone $(P)$ for $15 \mathrm{~min}$ in the presence or absence of the pure PR antagonist ORG $31710(\mathrm{ORG}-1 \mu \mathrm{M})$, the MEK inhibitor PD98059 (PD $-5 \mu \mathrm{M})$, the PI3K inhibitor wortmannin (WM - 30 nM), the G protein inhibitor PTX $(100 \mathrm{ng} / \mathrm{ml})$, and the Src kinase inhibitor PP2 $(10 \mu \mathrm{M})$, or exposed to the inhibitors alone. Cell contents of wild-type or phosphorylated FAK are shown. p-FAK densitometry values were adjusted to FAK intensity, and were then normalized to the control sample. ${ }^{\star \star} P<0.01$ versus control; ${ }^{\# \#} P<0.01$ versus $P$. (B) T47-D cells were transfected with scrambled siRNA or ERK1/2-targeted siRNAs for $48 \mathrm{~h}$. ERK1/2 protein expression was detected by western blot, and $\beta$-actin intensity was used as loading control. (C) Cells were exposed to $10 \mathrm{nM} P$ for 15 min after transfection with $100 \mathrm{nM}$ targeted siRNAs for ERK $1 / 2$ or control scrambled siRNAs for $48 \mathrm{~h}$. Cell contents of wild-type or phosphorylated FAK are shown. (D) T47-D cells were treated with $10 \mathrm{nM} P$ for $15 \mathrm{~min}$ with or without the Src kinase inhibitor PP2 $(10 \mu \mathrm{M})$. Phosphorylated (active) Akt (pAkt) was analyzed with western blot, and densitometry values were normalized to the control. ${ }^{\star *} P<0.01$ versus control; ${ }^{\# \#} P<0.01$ versus $P$. (E) T47-D cells were exposed to $10 \mathrm{nM} P$ for 15 min after transfection with $100 \mathrm{nM} \mathrm{c-Src} \mathrm{siRNAs} \mathrm{or} \mathrm{control} \mathrm{scrambled} \mathrm{siRNAs} \mathrm{for} 48 \mathrm{~h}$. Total c-Src, Akt, FAK, and phosphorylated Akt and FAK amounts following western blot and densitometric analysis are shown. ${ }^{\star \star} P<0.01$ versus corresponding scrambled control. (F) Cells were exposed to $10 \mathrm{nM} \mathrm{P}$ for $15 \mathrm{~min}$ after transfection with wild-type p85 $\alpha$ (WT p85 $\alpha, 1.5 \mu \mathrm{g})$ or dominant-negative $\mathrm{p} 85 \alpha(\Delta \mathrm{p} 85 \alpha, 1.5 \mu \mathrm{g})$ for $48 \mathrm{~h}$. Cell contents of $\mathrm{p} 85 \alpha$, wild-type, and phosphorylated FAK and densitometry values are shown. ${ }^{\star \star} P<0.01$ versus corresponding control without transfection. All these experiments were performed in triplicates, and representative images are shown.

The progesterone-dependent activation of RhoA/ ROCK-2 was mediated by c-Src and PI3K, since inhibitors of both kinases blocked the activation of RhoA and ROCK-2 by progesterone (Fig. 3A and B). In line with this, $\mathrm{c}-\mathrm{Src}$ silencing with siRNAs blocked progesterone-induced RhoA activation, which was also impaired by transfection of T47-D cells with $\Delta \mathrm{p} 85 \alpha$ (Fig. 3E). On the contrary, transfection of WT p85 $\alpha$ increased RhoA activation in the presence or absence of progesterone (Fig. 3E). 
A

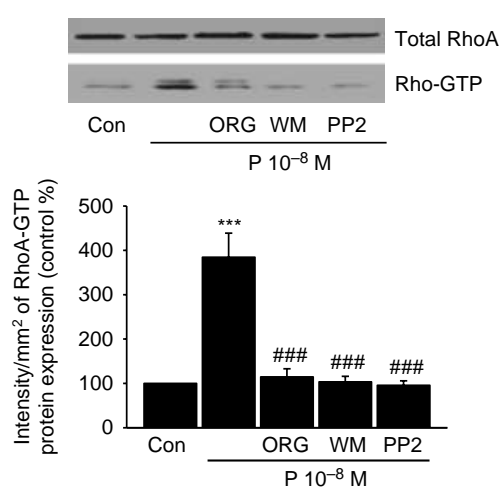

B
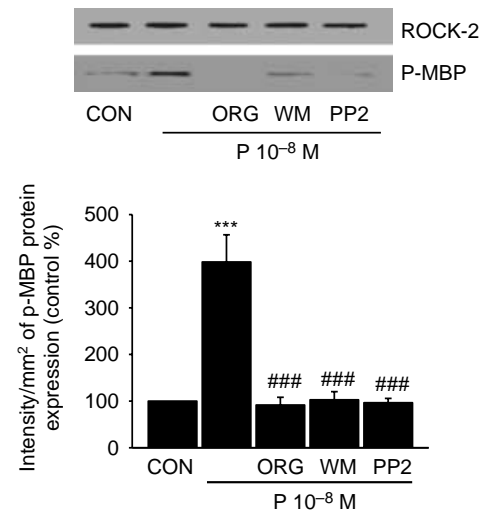

C
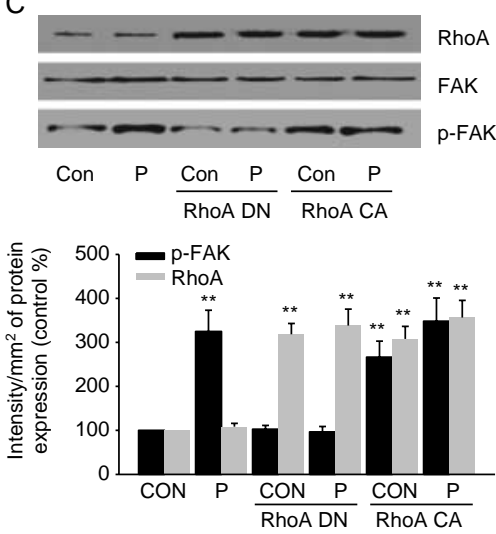

D
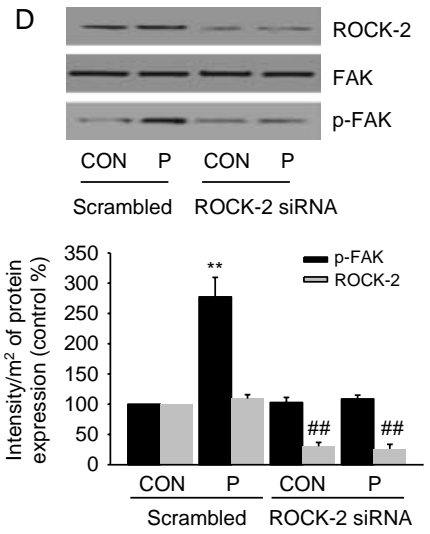

$\mathrm{E}$
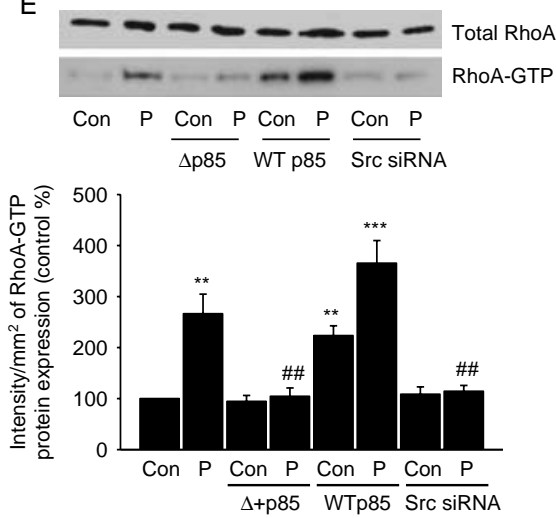

Figure 3 RhoA and ROCK-2 are activated during PR signaling to FAK. (A) RhoA activity was assayed in cells treated with progesterone $(\mathrm{P})(10 \mathrm{nM})$ for $15 \mathrm{~min}$ in the presence or absence of the pure PR antagonist ORG 31710 (ORG - $1 \mu \mathrm{M})$, the PI3K inhibitor wortmannin (WM $-30 \mathrm{nM})$, or the Src kinase inhibitor PP2 $(10 \mu \mathrm{M})$. Active, GTP-bound RhoA was immunoprecipitated with Rhotekin, and was subsequently assayed with western analysis with an anti-RhoA antibody (lower boxes). The upper blot shows total RhoA content in the input. RhoA-GTP densitometry values were adjusted to total RhoA intensity, and were then normalized to the control sample. ${ }^{\star \star \star} P<0.001$ versus control; ${ }^{\# \# \#} P<0.001$ versus $P$. (B) Cells were treated with 10 nM $P$ for 15 min in the presence or absence of ORG $31710(\mathrm{ORG}-1 \mu \mathrm{M})$, wortmannin $(\mathrm{WM}-30 \mathrm{nM})$, and PP2 (10 $\mu \mathrm{M})$. ROCK-2 was immunoprecipitated with a specific antibody, and the immunoprecipitates were used to phosphorylate the bait protein, myelin basic protein (MBP). ROCK-2 activity is shown as the amount of phosphorylated MBP (p-MBP). p-MBP densitometry values were adjusted to ROCK-2 intensity, and were then normalized to the control. ${ }^{* \star} P<0.001$ versus control; ${ }^{\# \# \#} P<0.001$ versus $P$. (C) T47-D cells were either mocktransfected or exposed to constitutively active or dominant-negative RhoA (RhoA CA or RhoA DN). Cells were then treated with $P$ $(10 \mathrm{nM})$ for $15 \mathrm{~min}$, and wild-type or phosphorylated FAK was analyzed. p-FAK and RhoA densitometry values were adjusted to FAK intensity, and were then normalized to the control. ${ }^{\star \star} P<0.01$ versus corresponding control without transfection. (D) Cells were exposed to $10 \mathrm{nM} P$ for 15 min after transfection with $100 \mathrm{nM}$ siRNAs toward ROCK-2 or control scrambled siRNAs for $48 \mathrm{~h}$. p-FAK and ROCK densitometry values were adjusted to FAK intensity, and were then normalized to the control. ${ }^{\star \star} P<0.01$ versus corresponding scrambled control; ${ }^{\# \#} P<0.01$ versus corresponding scrambled control. (E) Cells were exposed to $10 \mathrm{nM} P$ for 15 min after transfection with wild-type p85 $\alpha$ (WT p85 $\alpha, 1.5 \mu \mathrm{g})$, dominant-negative p85 $\alpha(\Delta \mathrm{p} 85 \alpha, 1.5 \mu \mathrm{g})$, or c-Src siRNAs for $48 \mathrm{~h}$. Active, GTP-bound RhoA was assayed, and total RhoA content was analyzed in the input. RhoA-GTP densitometry values were adjusted to total RhoA intensity, and were then normalized to the control. ${ }^{\star \star} P<0.01$ versus control; ${ }^{\star \star \star} P<0.001$ versus control; ${ }^{\# \#} P<0.01$ versus $P$ without transfection. All these experiments were performed in triplicates, and representative images are shown.

\section{Intracellular events linking activation of PR to cell migration and invasion}

We further explored the role of FAK regulation by PR in breast cancer cell migration and invasion. Consistent with our previous work (Fu et al. 2008b), progesterone markedly enhanced horizontal migration (Fig. 4A and B). This effect was completely blocked by silencing FAK with siRNAs (Fig. 4A and B). The enhancement of cancer cell migration induced by progesterone was also prevented by blocking PR with ORG 31710, c-Src with PP2, PI3K with wortmannin, ROCK-2 with Y-27632, or MEK1/2 with PD98059 (Fig. 4C).

Progesterone also promoted breast cancer cell invasion of a three-dimensional matrix (Fig. 4D). The invasive behavior induced by progesterone was prevented by silencing FAK with siRNAs, and by the 
inhibitors of PR, c-Src, and PI3K cascades (Fig. 4D). In this experimental setting, a statistically significant inhibition of matrix invasion induced by progesterone was also found during blockade of MEK1/2.

\section{Discussion}

The major finding of this manuscript is the identification of a novel signaling avenue of PR to FAK that may enhance the ability of PR + breast cancer cells to migrate and invade the surrounding environment.

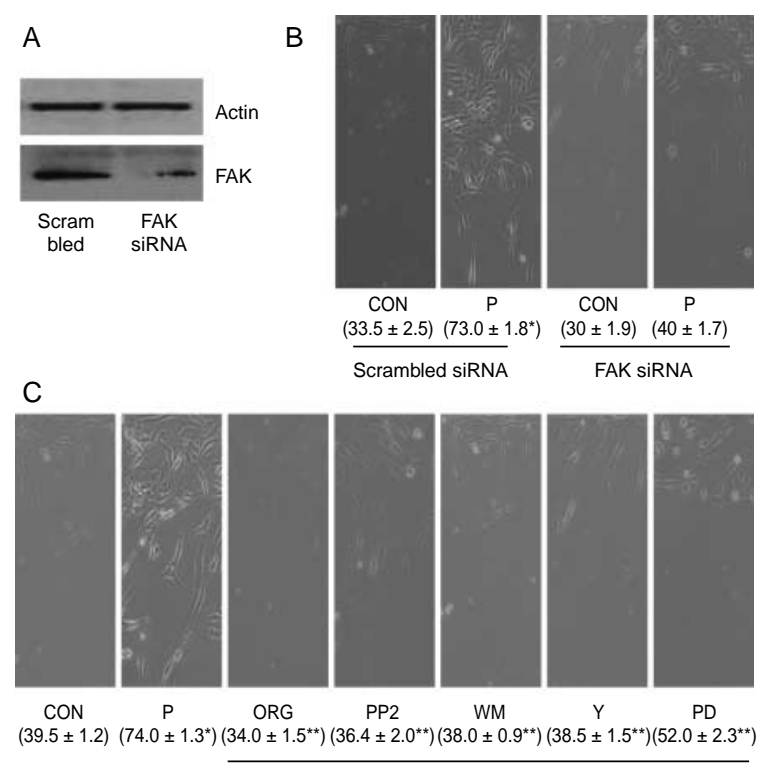

$\mathrm{P}$



Progesterone is a fundamental controller of breast development and function (Humphreys et al. 1997). On the other hand, exposure to progesterone can increase the chance of developing breast cancer, particularly when used after menopause together with estrogens (Ross et al. 2000, Schairer et al. 2000, Rossouw et al. 2002). In agreement, genetically modified animals lacking PR have a significantly lower incidence of mammary tumors compared with wildtype mice (Lydon et al. 1999). In addition, clinical and experimental evidence suggests that progesterone exposure may have a role in facilitating metastasis of $\mathrm{PR}+$ breast cancers to lymph nodes and distant organs (Weigelt et al. 2005), which is the main cause of morbidity and death due to this disease.

As potential mechanistic explanations, a number of studies reported that progesterone may enhance the invasiveness of breast cancer cells by increasing tissue factor or vascular endothelial growth factor expression (Hyder et al. 2001, Kato et al. 2005), or augmenting matrix metalloproteinases and urokinase-type plasminogen activator activities (Carnevale et al. 2007). Nevertheless, the effects of progesterone on breast cancer cell movement or invasion remain to date poorly characterized.

Cell movement is a complex and highly integrated process triggered by multiple signaling molecules and implemented by actin reorganization (Yamazaki et al. 2005). Rearrangement of actin fibers is the key to the formation of membrane protrusions at the leading edge. This process is modulated by sex steroids in human cells, including endothelial and breast cancer

Figure 4 Progesterone $(P)$ signaling to FAK increases T47-D cell migration and invasion. (A) T47-D cells were transfected with scrambled siRNA or FAK-targeted siRNAs for $48 \mathrm{~h}$. FAK protein expression was detected by western blot, and $\beta$-actin intensity was used as the loading control as indicated. (B) Cells were transfected with $100 \mathrm{nM}$ target siRNA for FAK or scrambled siRNA for $48 \mathrm{~h}$, and were then treated with $\mathrm{P}(10 \mathrm{nM})$ for $48 \mathrm{~h}$. (C) Cells were treated with $P(10 \mathrm{nM})$ for $48 \mathrm{~h}$ in the presence or absence of ORG $31710(\mathrm{ORG}-1 \mu \mathrm{M})$, PD98059 $(\mathrm{PD}-5 \mu \mathrm{M})$, wortmannin (WM - $30 \mathrm{nM}), \mathrm{Y}-27632(\mathrm{Y}-10 \mu \mathrm{M})$, or PP2 $(10 \mu \mathrm{M})$. Cell migration distances were measured, and values are presented within brackets as mean migration distance $(\mu \mathrm{m}) \pm$ s.D. ${ }^{*} P<0.01$ versus control; ${ }^{* \star} P<0.05$ versus $P$. The experiments were performed in triplicates, and representative images are shown. (D) T47-D cells were treated with $10 \mathrm{nM} \mathrm{P}$ for $24 \mathrm{~h}$ in the presence or absence of ORG 31710 (ORG - $1 \mu \mathrm{M})$, PD98059 (PD - $5 \mu \mathrm{M})$, wortmannin (WM - $30 \mathrm{nM})$, PP2 $(10 \mu \mathrm{M}), \mathrm{Y}-27632(\mathrm{Y}-10 \mu \mathrm{M})$ or after transfection with $100 \mathrm{nM}$ siRNAs toward FAK or control scrambled siRNAs for $48 \mathrm{~h}$. Cell invasion was assayed using invasion chambers. Invading cells were counted in three different central fields of triplicate membranes. Statistics for invasion indexes and representative images are shown. ${ }^{\star} P<0.01$ versus control; ${ }^{\star *} P<0.05$ versus $P$; ${ }^{\# \#} P<0.01$ versus $P$. The experiments were performed in triplicates. 
cells, as reported by us and others (Simoncini et al. 2006, Azios et al. 2007, Fu et al. 2008a,b, Giretti et al. 2008). Both estrogen and progesterone markedly increase the number of membrane lamellipodia and filopodia (Simoncini et al. 2006, Azios et al. 2007, Fu et al. 2008a,b, Giretti et al. 2008). These events are linked to the rapid activation by steroid receptors of actin-binding proteins belonging to the ERM family (Simoncini et al. 2006, Fu et al. 2008a,b, Giretti et al. 2008), and are elicited via rapid extranuclear signaling cascades involving cell membrane $\mathrm{G}$ proteins, c-Src, and the small GTPase RhoA/ROCK-2 complex (Simoncini et al. 2006, Fu et al. 2008a,b, Giretti et al. 2008). Cell adhesion to the ECM further requires the development of integrin-dependent adhesions to large extracellular proteins, which then mature into FA complexes by the recruitment of proteins such as the integrin-binding proteins paxillin, vinculin, talin, and p130CAS, along with the tyrosine kinases c-Src and FAK (Yamazaki et al. 2005). Tyr ${ }^{397}$ phosphorylation of FAK is critical in this process (Parsons 2003).

Here, we have found that progesterone rapidly activates $\mathrm{Tyr}^{397}$ phosphorylation of FAK, leading to the formation of FA complexes. FAK has been recently established as a central controller of cell migration, particularly during tumor metastasis. Overexpression of FAK is positively related to the metastatic behavior of various tumors, such as lung cancer (Fong et al. 2009), ovarian cancer (Hu et al. 2008), and melanomas (Kaneda et al. 2008). In human breast cancer samples, high FAK expression is associated with aggressive phenotype (Lark et al. 2005). In animal models, inhibition of FAK activity in a rat breast cancer metastasis model abrogated cancer diffusion to the lungs (van Nimwegen et al. 2005), and targeted deletion of FAK in mouse mammary epithelium reduced the pool of cancer stem/progenitor cells in primary tumors and blocked their self-renewal and migration (Luo et al. 2009). Using in vitro approaches, silencing of FAK in human and mouse mammary tumor cells transformed by activated Ras resulted in cell senescence and loss of invasive ability (Pylayeva et al. 2009). Overall, these findings highlight the relevance of the activity of FAK for cancer progression. The identification of FAK regulation by progesterone may thus offer important mechanistic insights to better understand the role of this hormone in breast cancer metastasis.

Interestingly, the phosphorylation of FAK induced by progesterone is achieved via extranuclear signaling cascades (Fu \& Simoncini 2007). Such mechanisms of actions are enacted through a variety of protein-protein interactions of PRs with kinases and other signaling intermediates taking place within the cell or at the cell membrane (Fu \& Simoncini 2007). Although the definition of the exact intracellular site where the signaling process of PR is started is outside the scope of this manuscript, there is a chance that a membraneinitiated process might be activated in this setting. Indeed, the existence of membrane-localized PRs in different tissues is well established (Zhu et al. 2003a,b, Karteris et al. 2006). Recently, a new putative progesterone-binding protein localized at the cell membrane, named PR membrane component 1 , has been identified in different tissues, including cancer cells (Craven 2008). Consistent with the hypothesis of a membrane-initiated signal, rapid phosphorylation of FAK in MCF-7 breast cancer cells has been described and linked to membrane androgen receptors (Kallergi et al. 2007). Whatever be the sub-cellular localization of PR that is required to start the chain of events leading to the activation of FAK, the present findings concur with previous literature in suggesting that extranuclear mechanisms of action of steroids receptors may be relevant in regulating motility and invasiveness of hormone-sensitive cancers.

Along with the evidence of rapid regulatory actions, progesterone may also alter FAK activity through conventional nuclear actions (Fu \& Simoncini 2008). For instance, MDA-MB-231 breast cancer cells transfected with PR and exposed long term to progesterone display an increased expression and phosphorylation of FAK and the formation of FA complexes, resulting in enhanced cell migration and invasion (Lin et al. 2000). Interestingly, in that work, the monoclonal antibody to $\beta 1$-integrins inhibited progesterone-induced FA and tyrosine phosphorylation of FAK, suggesting that $\beta 1$-integrins play an essential role in this action. Moreover, it has been reported that integrin-regulated linkages activate FAK and the formation of FAK-Src complexes which function to promote cell motility (Mitra \& Schlaepfer 2006). Although there has been evidence showing that progesterone regulates a number of integrins in T-47D cells (McGowan et al. 2004), the relevance of integrin in progesterone-induced rapid activation of FAK remains unclear, and will be the objective of future studies.

Progesterone results in enhanced cell migration and invasion, which could be regarded as the long-term biological functions. Of note, the rapid activation of FAK is a short-term action induced by progesterone. Although our data found a tight relationship between FAK activation and cell motility, the overall contribution of this rapid action to the long-term migration and invasion remains to be clarified ( $\mathrm{Fu} \&$ Simoncini 2007). 
$\mathrm{Tyr}^{397}$ phosphorylation of the FAK domain is a critical step for obtaining full enzymatic activity (Hanks et al. 2003, Hsia et al. 2003). Binding of cell membrane integrins to the ECM, or the activation of growth factor receptors catalyzes $\mathrm{Tyr}^{397}$ phosphorylation, inducing the interaction of this site with a number of signaling effectors (Zeng et al. 2003, Aponte et al. 2008). c-Src acts as a central hub in this cascade of events, relaying upstream signals to FAK as well as conveying messages from FAK to downstream effectors (van Nimwegen \& van de Water 2007). In agreement with this established model, we found that $\mathrm{c}-\mathrm{Src}$ is required for the PR-dependent activation of FAK. This is also consistent with the known ability of PR to interact in a ligand-induced manner with c-Src (Boonyaratanakornkit et al. 2001) that has been identified in breast cancer cells also (Fu et al. 2008a).

$\mathrm{PI} 3 \mathrm{~K}$ is one of the downstream effectors of c-Src (Koga et al. 2006). In our experimental setting, we identified that PI3K is downstream of c-Src in progesterone signaling, and we showed that this step is required for FAK activation. This is consistent with previous reports showing that the c-Src/PI3K pathway is implicated in $\mathrm{Tyr}^{397}$ FAK phosphorylation (Reiske et al. 1999, Thamilselvan et al. 2007). PR-dependent PI3K activation results in the activation of the RhoA/ROCK-2 cascade, and through this means, it increases FAK activity in breast cancer cells. A similar role of the RhoA/ROCK cascade has been established in cardiac myocytes and in other tumor cells, where it mediates FAK activation (Torsoni et al. 2005, Joshi et al. 2008). However, the mechanism through which RhoA/ROCK-2 drives FAK phosphorylation is still not completely understood. It may also be possible that RhoA/ROCK-2 induces actin cytoskeleton remodeling, which in turn leads to FAK activation since it has been reported that actin polymerization and stretch induce FAK phosphorylation.

Interestingly, the RhoA/ROCK/FAK cascade is also recruited following caveolin-1 phosphorylation (Joshi et al. 2008). Caveolin-1 functions as a molecular switch for some of the extranuclear actions of sex steroids, and progesterone is able to regulate this protein (Salatino et al. 2006, Sotgia et al. 2006). It would thus be interesting to clarify the role of caveolin-1 in progesterone-associated breast cancer cell migration and invasion.

On the other hand, although RhoA/ROCK mediates some of the signal transduction between PI3K and FAK, it may also be possible that PI3K directly interacts with FAK in the presence of progesterone, since binding of the p 85 regulatory subunit of PI3K to
FAK has been shown to trigger its phosphorylation (Reiske et al. 1999, Thamilselvan et al. 2007), and phosphorylated FAK is known to interact with p85 to increase its activity, thus creating a positive feedback loop (Del Re et al. 2008). The full characterization of the functional interrelation between PI3K and FAK during progesterone exposure is therefore not solved, and will require future studies.

In conclusion, we have shown that progesterone promotes breast cancer cell movement and invasion by triggering the formation of FA complexes. This is elicited by the activation of FAK. In the presence of progesterone, PR activates $\mathrm{c}-\mathrm{Src}$ and $\mathrm{PI} 3 \mathrm{~K} / \mathrm{Akt}$, leading to RhoA/ROCK-2 activation, which eventually phosphorylates FAK at $\mathrm{Tyr}^{397}$. Our results provide original mechanistic insights into the effects of progesterone on breast cancer progression, and may in future be helpful to develop new drugs against endocrine-sensitive breast cancers.

\section{Declaration of interest}

The authors declare that there is no conflict of interest that could be perceived as prejudicing the impartiality of the research reported.

\section{Funding}

This project was supported by PRIN grant from the Italian University and Scientific Research Ministry (MIUR) (to T Simoncini, Grant No: 2004057090_007) and by Scientific Research Foundation for Returned Scholars, Ministry of Education of China (to X-D Fu, Grant No: 4115015).

\section{Author contribution statement}

$\mathrm{X}-\mathrm{D} \mathrm{Fu}$ and L Goglia carried out the majority of the experiments and drafted the manuscript; A M Sanchez performed the ROCK-2 assay; M Flamini performed the migration experiment; M S Giretti and V Tosi performed the RhoA activity assay; A R Genazzani was instrumental in funding the study and participated in the writing of the manuscript; $T$ Simoncini planned and funded the project, supervised the experiments, and wrote the manuscript.

\section{References}

Anderson GL, Limacher M, Assaf AR, Bassford T, Beresford SA, Black H, Bonds D, Brunner R, Brzyski R, Caan $\mathrm{B}$ et al. 2004 Effects of conjugated equine estrogen in postmenopausal women with hysterectomy: the Women's Health Initiative randomized controlled trial. Journal of the American Medical Association 291 1701-1712. 
Aponte M, Jiang W, Lakkis M, Li MJ, Edwards D, Albitar L, Vitonis A, Mok SC, Cramer DW \& Ye B 2008 Activation of platelet-activating factor receptor and pleiotropic effects on tyrosine phospho-EGFR/Src/FAK/paxillin in ovarian cancer. Cancer Research 68 5839-5848.

Arnaout MA, Goodman SL \& Xiong JP 2007 Structure and mechanics of integrin-based cell adhesion. Current Opinion in Cell Biology 19 495-507.

Azios NG, Krishnamoorthy L, Harris M, Cubano LA, Cammer M \& Dharmawardhane SF 2007 Estrogen and resveratrol regulate $\mathrm{Rac}$ and $\mathrm{Cdc} 42$ signaling to the actin cytoskeleton of metastatic breast cancer cells. Neoplasia 9 147-158.

Boonyaratanakornkit V, Scott MP, Ribon V, Sherman L, Anderson SM, Maller JL, Miller WT \& Edwards DP 2001 Progesterone receptor contains a proline-rich motif that directly interacts with $\mathrm{SH} 3$ domains and activates c-Src family tyrosine kinases. Molecular Cell 8 269-280.

Carnevale RP, Proietti CJ, Salatino M, Urtreger A, Peluffo G, Edwards DP, Boonyaratanakornkit V, Charreau EH, Bal de Kier Joffe E, Schillaci R et al. 2007 Progestin effects on breast cancer cell proliferation, proteases activation, and in vivo development of metastatic phenotype all depend on progesterone receptor capacity to activate cytoplasmic signaling pathways. Molecular Endocrinology 21 1335-1358.

Christofori G 2006 New signals from the invasive front. Nature 441 444-450.

Craven RJ 2008 PGRMC1: a new biomarker for the estrogen receptor in breast cancer. Breast Cancer Research 10113.

Del Re DP, Miyamoto S \& Brown JH 2008 Focal adhesion kinase as a RhoA-activable signaling scaffold mediating Akt activation and cardiomyocyte protection. Journal of Biological Chemistry 283 35622-35629.

Fong YC, Liu SC, Huang CY, Li TM, Hsu SF, Kao ST, Tsai FJ, Chen WC, Chen CY \& Tang CH 2009 Osteopontin increases lung cancer cells migration via activation of the alphavbeta3 integrin/FAK/Akt and NF-kappaB-dependent pathway. Lung Cancer 64 263-270.

Fu XD \& Simoncini T 2007 Non-genomic sex steroid actions in the vascular system. Seminars in Reproductive Medicine 25 178-186.

Fu XD \& Simoncini T 2008 Extra-nuclear signaling of estrogen receptors. IUBMB Life 60 502-510.

Fu XD, Flamini M, Sanchez AM, Goglia L, Giretti MS, Genazzani AR \& Simoncini T 2008a Progestogens regulate endothelial actin cytoskeleton and cell movement via the actin-binding protein moesin. Molecular Human Reproduction 14 225-234.

Fu XD, Giretti MS, Baldacci C, Garibaldi S, Flamini M, Sanchez AM, Gadducci A, Genazzani AR \& Simoncini T $2008 b$ Extra-nuclear signaling of progesterone receptor to breast cancer cell movement and invasion through the actin cytoskeleton. PLOS ONE 3 e2790.

Giretti MS, Fu XD, De Rosa G, Sarotto I, Baldacci C, Garibaldi S, Mannella P, Biglia N, Sismondi P,
Genazzani AR et al. 2008 Extra-nuclear signalling of estrogen receptor to breast cancer cytoskeletal remodelling, migration and invasion. PLoS ONE 3 e2238.

Grem JL, Geoffroy F, Politi PM, Cuddy DP, Ross DD, Nguyen D, Steinberg SM \& Allegra CJ 1995

Determinants of sensitivity to 1-beta-D-arabinofuranosylcytosine in HCT 116 and NCI-H630 human colon carcinoma cells. Molecular Pharmacology 48 305-315.

Hankinson SE \& Eliassen AH 2007 Endogenous estrogen, testosterone and progesterone levels in relation to breast cancer risk. Journal of Steroid Biochemistry and Molecular Biology 106 24-30.

Hanks SK, Ryzhova L, Shin NY \& Brabek J 2003 Focal adhesion kinase signaling activities and their implications in the control of cell survival and motility. Frontiers in Bioscience 8 d982-d996.

Hsia DA, Mitra SK, Hauck CR, Streblow DN, Nelson JA, Ilic D, Huang S, Li E, Nemerow GR, Leng J et al. 2003 Differential regulation of cell motility and invasion by FAK. Journal of Cell Biology 160 753-767.

Hu XW, Meng D \& Fang J 2008 Apigenin inhibited migration and invasion of human ovarian cancer A2780 cells through focal adhesion kinase. Carcinogenesis 29 2369-2376.

Humphreys RC, Lydon JP, O’Malley BW \& Rosen JM 1997 Use of PRKO mice to study the role of progesterone in mammary gland development. Journal of Mammary Gland Biology and Neoplasia 2 343-354.

Hwang KC, Lee KH \& Jang Y 2002 Inhibition of MEK1,2/ERK mitogenic pathway by estrogen with antiproliferative properties in rat aortic smooth muscle cells. Journal of Steroid Biochemistry and Molecular Biology 80 85-90.

Hyder SM, Chiappetta C \& Stancel GM 2001 Pharmacological and endogenous progestins induce vascular endothelial growth factor expression in human breast cancer cells. International Journal of Cancer 92 469-473.

Joshi B, Strugnell SS, Goetz JG, Kojic LD, Cox ME, Griffith OL, Chan SK, Jones SJ, Leung SP, Masoudi H et al. 2008 Phosphorylated caveolin-1 regulates Rho/ROCKdependent focal adhesion dynamics and tumor cell migration and invasion. Cancer Research 68 8210-8220.

Kallergi G, Agelaki S, Markomanolaki H, Georgoulias V \& Stournaras C 2007 Activation of FAK/PI3K/Rac1 signaling controls actin reorganization and inhibits cell motility in human cancer cells. Cellular Physiology and Biochemistry 20 977-986.

Kaneda T, Sonoda Y, Ando K, Suzuki T, Sasaki Y, Oshio T, Tago M \& Kasahara T 2008 Mutation of Y925F in focal adhesion kinase (FAK) suppresses melanoma cell proliferation and metastasis. Cancer Letters 270 354-361.

Karteris E, Zervou S, Pang Y, Dong J, Hillhouse EW, Randeva HS \& Thomas P 2006 Progesterone signaling in human myometrium through two novel membrane $G$ protein-coupled receptors: potential role in functional progesterone withdrawal at term. Molecular Endocrinology 20 1519-1534. 
Kato S, Pinto M, Carvajal A, Espinoza N, Monso C, Sadarangani A, Villalon M, Brosens JJ, White JO, Richer JK et al. 2005 Progesterone increases tissue factor gene expression, procoagulant activity, and invasion in the breast cancer cell line ZR-75-1. Journal of Clinical Endocrinology and Metabolism 90 1181-1188.

Koga F, Xu W, Karpova TS, McNally JG, Baron R \& Neckers L 2006 Hsp90 inhibition transiently activates Src kinase and promotes Src-dependent Akt and Erk activation. PNAS 103 11318-11322.

Lark AL, Livasy CA, Dressler L, Moore DT, Millikan RC, Geradts J, Iacocca M, Cowan D, Little D, Craven RJ et al. 2005 High focal adhesion kinase expression in invasive breast carcinomas is associated with an aggressive phenotype. Modern Pathology 18 1289-1294.

Lin VC, Ng EH, Aw SE, Tan MG, Ng EH \& Bay BH 2000 Progesterone induces focal adhesion in breast cancer cells MDA-MB-231 transfected with progesterone receptor complementary DNA. Molecular Endocrinology 14 348-358.

Luo M, Fan H, Nagy T, Wei H, Wang C, Liu S, Wicha MS \& Guan JL 2009 Mammary epithelial-specific ablation of the focal adhesion kinase suppresses mammary tumorigenesis by affecting mammary cancer stem/ progenitor cells. Cancer Research 69 466-474.

Lydon JP, Ge G, Kittrell FS, Medina D \& O’Malley BW 1999 Murine mammary gland carcinogenesis is critically dependent on progesterone receptor function. Cancer Research 59 4276-4284.

McGowan EM, Saad S, Bendall LJ, Bradstock KF \& Clarke CL 2004 Effect of progesterone receptor a predominance on breast cancer cell migration into bone marrow fibroblasts. Breast Cancer Research and Treatment $\mathbf{8 3}$ 211-220.

Mitra SK \& Schlaepfer DD 2006 Integrin-regulated FAK-Src signaling in normal and cancer cells. Current Opinion in Cell Biology 18 516-523.

van Nimwegen MJ \& van de Water B 2007 Focal adhesion kinase: a potential target in cancer therapy. Biochemical Pharmacology 73 597-609.

van Nimwegen MJ, Verkoeijen S, van Buren L, Burg D \& van de Water B 2005 Requirement for focal adhesion kinase in the early phase of mammary adenocarcinoma lung metastasis formation. Cancer Research $\mathbf{6 5}$ 4698-4706.

Owens LV, Xu L, Craven RJ, Dent GA, Weiner TM, Kornberg L, Liu ET \& Cance WG 1995 Overexpression of the focal adhesion kinase (p125FAK) in invasive human tumors. Cancer Research 55 2752-2755.

Parsons JT 2003 Focal adhesion kinase: the first ten years. Journal of Cell Science 116 1409-1416.

Pylayeva Y, Gillen KM, Gerald W, Beggs HE, Reichardt LF \& Giancotti FG 2009 Ras- and PI3K-dependent breast tumorigenesis in mice and humans requires focal adhesion kinase signaling. Journal of Clinical Investigation 119 252-266.
Reiske HR, Kao SC, Cary LA, Guan JL, Lai JF \& Chen HC 1999 Requirement of phosphatidylinositol 3-kinase in focal adhesion kinase-promoted cell migration. Journal of Biological Chemistry 274 12361-12366.

Romer LH, Birukov KG \& Garcia JG 2006 Focal adhesions: paradigm for a signaling nexus. Circulation Research 98 606-616.

Ross RK, Paganini-Hill A, Wan PC \& Pike MC 2000 Effect of hormone replacement therapy on breast cancer risk: estrogen versus estrogen plus progestin. Journal of the National Cancer Institute 92 328-332.

Rossouw JE, Anderson GL, Prentice RL, LaCroix AZ, Kooperberg C, Stefanick ML, Jackson RD, Beresford SA, Howard BV, Johnson KC et al. 2002 Risks and benefits of estrogen plus progestin in healthy postmenopausal women: principal results From the Women's Health Initiative randomized controlled trial. Journal of the American Medical Association 288 321-333.

Rousell RH, Hewett AJ, McEwen J, Allen RM, Adams K \& Redshaw MR 1979 Determination of serum progesterone levels using a direct ${ }^{125}$ I-radioimmunoassay. La Ricerca in Clinica e in Laboratorio 9 185-195.

Rovin JD, Frierson HF Jr, Ledinh W, Parsons JT \& Adams RB 2002 Expression of focal adhesion kinase in normal and pathologic human prostate tissues. Prostate $\mathbf{5 3}$ 124-132.

Salatino M, Beguelin W, Peters MG, Carnevale R, Proietti CJ, Galigniana MD, Vedoy CG, Schillaci R, Charreau EH, Sogayar MC et al. 2006 Progestin-induced caveolin-1 expression mediates breast cancer cell proliferation. Oncogene 25 7723-7739.

Schairer C, Lubin J, Troisi R, Sturgeon S, Brinton L \& Hoover R 2000 Menopausal estrogen and estrogenprogestin replacement therapy and breast cancer risk. Journal of the American Medical Association 283 485-491.

Simoncini T, Hafezi-Moghadam A, Brazil DP, Ley K, Chin WW \& Liao JK 2000 Interaction of oestrogen receptor with the regulatory subunit of phosphatidylinositol-3-OH kinase. Nature 407 538-541.

Simoncini T, Scorticati C, Mannella P, Fadiel A, Giretti MS, Fu XD, Baldacci C, Garibaldi S, Caruso A, Fornari L et al. 2006 Estrogen receptor alpha interacts with Galpha13 to drive actin remodeling and endothelial cell migration via the RhoA/Rho kinase/moesin pathway. Molecular Endocrinology 20 1756-1771.

Sood AK, Coffin JE, Schneider GB, Fletcher MS, DeYoung BR, Gruman LM, Gershenson DM, Schaller MD \& Hendrix MJ 2004 Biological significance of focal adhesion kinase in ovarian cancer: role in migration and invasion. American Journal of Pathology 165 1087-1095.

Sotgia F, Rui H, Bonuccelli G, Mercier I, Pestell RG \& Lisanti MP 2006 Caveolin-1, mammary stem cells, and estrogen-dependent breast cancers. Cancer Research $\mathbf{6 6}$ 10647-10651. 
Thamilselvan V, Craig DH \& Basson MD 2007 FAK association with multiple signal proteins mediates pressure-induced colon cancer cell adhesion via a Src-dependent PI3K/Akt pathway. FASEB Journal 21 1730-1741.

Torsoni AS, Marin TM, Velloso LA \& Franchini KG 2005 RhoA/ROCK signaling is critical to FAK activation by cyclic stretch in cardiac myocytes. American Journal of Physiology. Heart and Circulatory Physiology 289 H1488-H1496.

Weigelt B, Peterse JL \& van't Veer LJ 2005 Breast cancer metastasis: markers and models. Nature Reviews. Cancer 5 591-602.

Yager JD \& Davidson NE 2006 Estrogen carcinogenesis in breast cancer. New England Journal of Medicine 354 270-282.

Yamaguchi H, Wyckoff J \& Condeelis J 2005 Cell migration in tumors. Current Opinion in Cell Biology 17 559-564.
Yamazaki D, Kurisu S \& Takenawa T 2005 Regulation of cancer cell motility through actin reorganization. Cancer Science 96 379-386.

Zeng L, Si X, Yu WP, Le HT, Ng KP, Teng RM, Ryan K, Wang DZ, Ponniah S \& Pallen CJ 2003 PTP alpha regulates integrin-stimulated FAK autophosphorylation and cytoskeletal rearrangement in cell spreading and migration. Journal of Cell Biology 160 137-146.

Zhu Y, Bond J \& Thomas P $2003 a$ Identification, classification, and partial characterization of genes in humans and other vertebrates homologous to a fish membrane progestin receptor. PNAS 100 2237-2242.

Zhu Y, Rice CD, Pang Y, Pace M \& Thomas P 2003b Cloning, expression, and characterization of a membrane progestin receptor and evidence it is an intermediary in meiotic maturation of fish oocytes. PNAS 100 2231-2236.

Ziegler WH, Liddington RC \& Critchley DR 2006 The structure and regulation of vinculin. Trends in Cell Biology 16 453-460. 